\title{
Comparison and Estimation of Four Infiltration Models
}

\author{
Atta-Darkwa Thomas ${ }^{1 *}$, Antwi Eric Ofosu ${ }^{2}$, Amankwah Emmanuel ${ }^{1}$, Ankamah Johnson De-Graft ${ }^{3}$, \\ Akolgo Gilbert Ayine1, Austin Asare ${ }^{4}$, Antwi Alexander ${ }^{1}$
}

\footnotetext{
${ }^{1}$ Department of Mechanical and Manufacturing Engineering, University of Energy and Natural Resources, Sunyani, Ghana ${ }^{2}$ Department of Energy and Environmental Engineering, University of Energy and Natural Resources, Sunyani, Ghana ${ }^{3}$ Department of Mathematics and Statistics, University of Energy and Natural Resources, Sunyani, Ghana ${ }^{4}$ Department of Environmental Management, University of Energy and Natural Resources, Sunyani, Ghana Email: ^thomas.atta-darkwa@uenr.edu.gh,emmanuel.amankwah@uenr.edu.gh,gilbert.akolgo@uenr.edu.gh, alexanderscofields@gmail.com,eric.ofosu@uenr.edu.gh,johnson.ankamah@uenr.edu.gh, austin.asare@uenr.edu.gh
}

How to cite this paper: Thomas, A.-D., Ofosu, A.E., Emmanuel, A., De-Graft, A.J., Ayine, A.G., Asare, A. and Alexander, A. (2020) Comparison and Estimation of Four Infiltration Models. Open Journal of Soil Science, 10, 45-57.

https://doi.org/10.4236/ojss.2020.102003

Received: November 28, 2019

Accepted: February 18, 2020

Published: February 21, 2020

Copyright $\odot 2020$ by author(s) and Scientific Research Publishing Inc. This work is licensed under the Creative Commons Attribution International License (CC BY 4.0).

http://creativecommons.org/licenses/by/4.0/

\begin{abstract}
Infiltration is an important component of the hydrological cycle. It provides soil moisture in the vadose zone to support plant growth. This study was conducted to compare the validity of four infiltration models with measured values from the double ring infiltrometer. The parameters of the four models compared were estimated using the linear regression analysis. The C.C was used to show the performance of the predictability of the models. The RMSE, MAE and MBE were employed to check the anomalies between the predicted and the observed values. The results showed that, average values of the C.C ranged from $0.9294-0.9852$. The average values of the RMSE were 4.0033, $17.489,11.2400$ and 49.8448; MAE were 3.1341, 15.9802, 10.6525, and 61.4736; and MBE were 0.0786, 9.5755, -0.0007 and 47.0204 for Philip, Horton, Green Ampt and Kostiakov respectively for the wetland soils. Statistical results also from the Fisher's multiple comparison test show that the mean infiltration rate estimated from the Green Ampt's, Philip's and Horton's model was not significantly different $(p>0.05)$ from the observed. The results indicated that the Kostiakov's model had the highest deviations as it overestimated the measured data in all the plots. Comparison of the statistical parameters C.C, RMSE, MAE, and MBE for the four models indicates that the Philip's model agreed well with the measured data and therefore, performed better than the Green Ampt's, Horton's and Kostiakov's models respectively in that order for Besease wetland soils. Estimation of infiltration rate by the Philip's model is important in the design of irrigation schemes and scheduling. Therefore, in the absence of measured infiltration data, the Philip's model could be used to produce infiltration information for inland valley bottom
\end{abstract}


soils that exhibit similar characteristic as Besease wetland soils.

\section{Keywords}

Wetland, Infiltration Models, Irrigation, Philip's Model, Ring Infiltrometer

\section{Introduction}

Infiltration is the process by which water on the ground surface enters the soil. Infiltration plays a vital role in soil and water conservation as it determines the amount of runoff over the soil surface during irrigation and precipitation. The infiltration rate of a soil, thus ability of the soil to accept heavy rainfall or irrigation depends on the characteristics of the soil [1] [2]. Substantial reduction in time and cost of field measurement of infiltration can be achieved by using infiltration models [3]. Poor infiltration rate indicates potential of high runoff and erosion which affects the amount of water stored in the plant root zone [4]. This makes it difficult for the soil to meet the required water demand for crop production.

Design, operation and management of surface irrigation system rely greatly on the infiltration behaviour or characteristics of the soil, because the infiltration behaviour of the soil directly determines the essential variables such as inflow rate, length of run, application time and depth of percolation [5]. These infiltration characteristics of the soil are determined when fitted mathematically into infiltration models. But not all infiltration models can be applied to all soils [1]. Many researchers have compared the accuracy of the various models by comparing the computed and observed infiltration rates. Under different conditions, a particular model shows better predictions than others. But till date, it is not specifically mentioned which model gives the best prediction [6].

[7] estimated and compared Kostiakov, Novel and the Modified Kostiakov infiltration models in the Kurukshetra district of India. They concluded that, the Novel model was more accurate in predicting infiltration rate. [8] investigated the capability of the novel infiltration model in estimating the infiltration rate from actual field data in comparison to Philip, Kostiakov and Modified Kostiakov models in similar conditions. Findings from their research indicated that the novel model was the most suitable among three other models used for the estimation of infiltration rate of the study area. [9] also compared Philip's model, modified Philip's model, Horton's model, and Green Ampt's model in NIT Kurukshetra campus in India at ten different locations to predict infiltration rates and found out that, the infiltration rate versus time plot for the field data and predicted data did not accurately match; but the Modified Philip's model was much closer to the observed field data. [10] carried out infiltration studies of different soil under different soil conditions and compared the infiltration models with field data measured by Double-ring infiltrometer. They reported that the 
Horton's model, and the Green Ampt's model were the best fitting to the observed field date to estimate infiltration rate at any given time with high degree of correlation coefficient and minimum degree of standard error. [11] also compared the Kostiakov's model, Modified Kostiakov's model, Philips model, and Horton's model on a sandy soil in Lafia, Southern Guinea Savana Zone of Nigeria. They observed that, although the other models produced good overall agreement with the field measured cumulative infiltration depth, the Horton's model gave the best fit to the measured cumulative infiltration. [1] reported that Philip's model was more suitable than Kostiakov's model under the Incesptisols in the humid forest zone of Nigeria.

The study sought to evaluate the performance of four infiltration models (Kostiakov's, Philips, Horton's and Green Ampt) to determine their suitability for predicting infiltration rates for Besease wetland soils.

\section{Study Area}

Besease is a predominantly farming area in the Ejisu Municipal District of the Ashanti Region in Ghana. The site lies within Latitude $1^{\circ} 15^{\prime} \mathrm{N}$ and $1^{\circ} 45^{\prime} \mathrm{N}$ and Longitude $6^{\circ} 15^{\prime} \mathrm{W}$ and $7^{\circ} 00^{\prime} \mathrm{W}$. The study area covers about 72 ha of the valley bottom lands at Besease (Figure 1). The climate of the study area is mostly related to the semi-humid type. The region is characterised with two distinct seasons, the wet season which begins from April and ends in October while the dry season extends from the month of November to March. The wet seasons can be categorised less than two rainy seasons. The major rainy season which ranges from mid-March to July and the minor rainy season starts from September to mid-November. The mean annual rainfall is $1420 \mathrm{~mm}$; mean monthly temperature is $26.5^{\circ} \mathrm{C}$, the relative humidity ranges from $64 \%$ in January to $84 \%$ in $\mathrm{Au}$ gust. The average monthly maximum and minimum evapotranspiration (ETo) for the study area were $127.5 \mathrm{~mm}$ and $64.7 \mathrm{~mm}$ and has an annual ETo of 1230 $\mathrm{mm}$. The area is drained by the Oda River which is seasonal and whose basin is about $143 \mathrm{~km}^{2}$ [12].

The study area is located in the moist semi-deciduous forest zone. Grass species prominently found in the valley bottom are Santrocema trifolia, Chromolaeve ordorata, Imperata cylindrical, Mimosa pigra,Ceiba patendra, Centrosema pubescens and Mariscus flabelliformis. Plant species like Raphia hookeri (Raphia palm), Alstonia boonei, Malotus oppositifolius and Pseudospondias microcarpa extends along the margins of the Oda River. Soils of the Ejisu-Besease can be found in the soil map of Kumasi area. The study area lies in the Offin soil series which are grey to light brownish grey, poorly drained alluvial sands and clays developed within nearly flat but narrow valley bottoms along streams. The series have very slow internal drainage, very slow runoff, rapid permeability and moderate water holding capacity. The geology of the watershed is relatively heterogeneous and mainly composed of Phyllites, quartzite, shale, Tarkwain and Voltaian-sandstone and limestone. The Phyllites which underlie 59\% of the area 

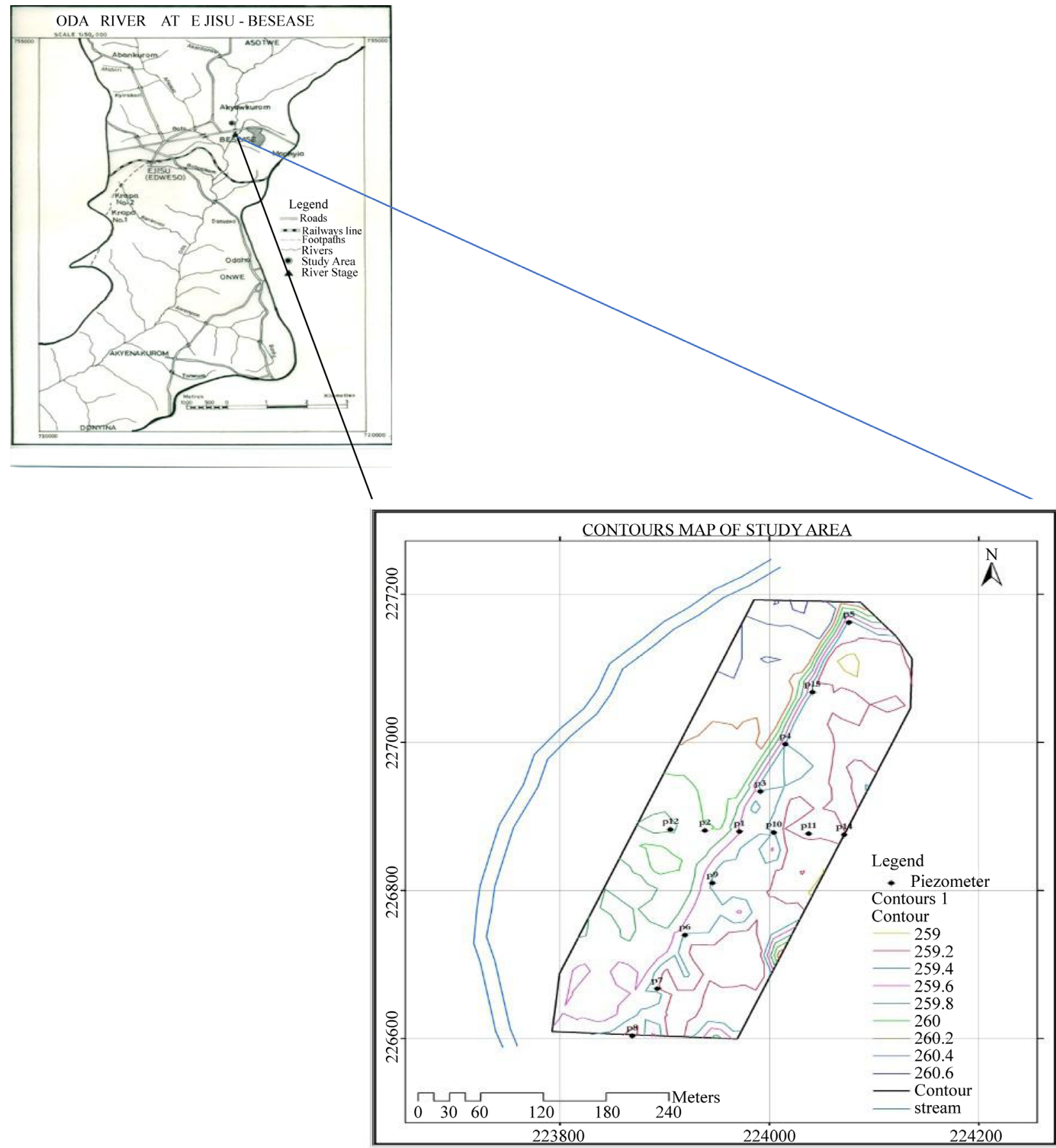

Figure 1. Map of Besease project site showing piezometric network.

consist of upper and lower Birimian rocks. Very few rock outcrops were encountered in the survey as the rocks are deeply weathered. The weathered phyllite is soft and easily broken, recognizable pieces and is typically found at $2-3 \mathrm{~m}$ below surface. Soils found within the Oda River catchment are grouped as those derived from granites, sandstones, alluvial materials, greenstone, andesite, schist and amphibolities. Specifically, the soils are Orthi-ferric Acrisol, Eutric Fluvisol, Gleyic Arenosols, Eutric Gleysols and Dystri-Haplic Nitisol. The Besease aquifer 
is composed of heterogeneous sequence of layers which is dominated by sand, clayey sand and silts. The valley bottom is developed by small holder farmers who cultivate rice in the wet season and also grow vegetables like cabbage, lettuce, bell pepper, cauliflower, cucumber and okra. Other cereals like maize are cultivated at the dry season when the water table is low.

\section{Materials and Methods}

\subsection{Sample Collection}

Soil samples were collected with core samplers of height $10 \mathrm{~cm}$ to an average depth of $100 \mathrm{~cm}$ (Figure 1). Disturbed soil samples were taken from the field at site P1 - P2, P1 - P9, P6 - P9, P7 - P8, P11 - P14, and P13 - P4 and air dried, ground and passed through the $2 \mathrm{~mm}$ sieve to obtain the soil fractions for the determination of soil texture.

\subsection{Measurement of Infiltration Rates}

Double ring infiltrometers, consisting of two concentric rings, were used to measure the infiltration rate. Rings were $250 \mathrm{~mm}$ deep and were made from 12-guage steel with sharpened bottom edges. They were driven into the ground to $50 \mathrm{~mm}$ depth. Grass was cut to near soil level and a pad was placed inside the inner ring to prevent puddling. The inner and outer edges were tamped to seal possible cracking. Generally, the water level was kept at or above $50 \mathrm{~mm}$ depth. The difference in height between the inner and outer rings was kept to a minimum. The rate of fall of water was measured in the inner ring while a pool of water was maintained at approximately the same level in the outer ring to reduce the amount of lateral flow from the inner ring. The rate of fall of the water level in the inner cylinder was measured at 2, 3, 5, 10, 15, 20, 30, 45 and 60 minutes and at 30-minute intervals thereafter. The accumulated volume of water entering the soil was converted to the infiltration rate $(\mathrm{mm} / \mathrm{h})$ and was plotted against elapsed time whereby a declining slope was obtained. Fifty-five (55) samples (replicates) were used for the measurement of soil infiltration rate. The field infiltration rate measurement was considered as observed. The aim of the measurements was to obtain a steady-state infiltration rate. This is achieved when the amount of infiltrated water was constant in time, i.e. when the infiltration curve (instantaneous infiltration against time) levels out. To estimate the infiltration rate at steady state, the terminal infiltration rate (i.e. the infiltration rate obtained at the end of the experiment in about $2 \mathrm{~h}$ ), was used as an approximation of the steady state infiltration rate.

\subsection{Infiltration Models and Parameters}

In this study, Kostiakov's, Philip's, Horton's and Green Ampt's infiltration models were fitted to the infiltration data.

\subsubsection{Kostiakov's Model [13]}

Kostiakov's model, an empirical model expresses cumulative infiltration equa- 
tion as

$$
F_{p}=a t^{b}
$$

where $F_{p}=$ cumulative infiltration $(\mathrm{cm}), t=$ time from start of infiltration ( $\min$ ), and $\mathrm{a}$ and $\mathrm{b}$ are constants that depends on the soil initial conditions. Where, $a>0$ and $0<b<1$.

The parameters in the Kostiakov equation are obtained from the plot of $\ln \left(F_{p}\right)$ versus $\ln (t)$ and the best fit straight line through the plotted points gives $\ln a$ as the intercept and $b$ as the slope.

\subsubsection{Philip's Model [14]}

Philip's physical based model expresses infiltration rate as

$$
f_{p}=\frac{1}{2} s t^{-1 / 2}+K
$$

where $f_{p}=$ Infiltration capacity $(\mathrm{cm} / \mathrm{h})$ at any time $t(\mathrm{~min})$ from the start, $S=$ soil water sorptivity which is a function of initial soil water content and $K=$ Darcy's hydraulic conductivity. The observed infiltration rate, $f_{p}$ values are plotted against the reciprocal square root of time, $t^{-\frac{1}{2}}$. The best fitting straight line through the plotted points gives $K$ as the intercept and $\frac{s}{2}$ as the slope of the line.

\subsubsection{Horton's Model [15]}

Horton's semi-empirical model expressed the decay of infiltration capacity with time as an exponential decay given by

$$
f_{p}=f_{c}+\left(f_{0}-f_{c}\right) e^{K_{h} t} \text { for } 0 \geq t \leq t_{c}
$$

where $f_{p}=$ infiltration capacity $(\mathrm{cm} / \mathrm{h})$ at any time $t(\mathrm{~min})$ from the start of the rainfall

$f_{0}=$ initial infiltration capacity $(\mathrm{cm} / \mathrm{h})$ at $t=0$

$f_{c}=$ final steady state infiltration capacity $(\mathrm{cm} / \mathrm{h})$ at $t=t_{c}$.

$K_{h}=$ Horton's decay coefficient which depends upon soil characteristic and vegetation cover. The parameters of the Horton's equation are determined by plotting the values of $\ln \left(f_{p}-f_{c}\right)$ against $t$ to obtain the best fit straight line through the plotted points. $\ln \left(f_{0}-f_{c}\right)$ depicts the intercept and the decay constant, $K_{h}$ represent the slope.

\subsubsection{Green Ampt's Model [16]}

Green Ampt proposed a model for infiltration capacity based on Darcy's law and expresses the physical model as

$$
f_{p}=m+n / F_{p}
$$

where $m$ and $n$ are Green Ampt's parameters of infiltration model. Values of infiltration capacity, $f_{p}$ are plotted against $\frac{1}{F_{P}}$ on an arithmetic graph. The in- 
tercept on the ordinate axis is $m$ and $n$ serves as the slope when the best fit straight line is drawn through the plotted points.

\subsection{Statistical Analysis}

\subsubsection{Coefficient of Correlation (C.C)}

Coefficient of correlation is a statistical measure that calculates the strength of the relationship between the relative movements of two variables. The coefficient of correlation is calculated as

$$
C C=\frac{z \sum a b-\left(\sum a\right)\left(\sum b\right)}{\sqrt{z\left(\sum a^{2}\right)}-\left(\sum a\right)^{2} \sqrt{z\left(\sum b^{2}\right)}-\left(\sum b\right)^{2}}
$$

\subsubsection{Root Mean square Error (RMSE)}

The root mean square error exaggerates the prediction error, thus the difference between the predicted value and the actual value. This is evaluated by

$$
R M S E=\sqrt{\frac{1}{N}\left(\sum_{i=1}^{n}\left(a_{i}-b_{i}\right)^{2}\right)}
$$

where $a$ is the calculated and $b$ is observed values of the infiltration rate and $N$ is the number of observations.

\subsubsection{Mean Bias Error (MBE)}

This is the average difference between the predicted values and the observed values of the infiltration models. The mean bias error is estimated by

$$
M B E=\frac{1}{N} \sum_{i=1}^{n}\left(a_{i}-b_{i}\right)^{2}
$$

where $a$ is the calculated and $b$ is observed values of the infiltration rate and $N$ is the number of observations.

\subsubsection{Mean Absolute Error (MAE)}

The absolute error is the absolute value of the difference between the predicted value and the observed value. The absolute error is estimated by

$$
M A E=\frac{1}{N} \sum_{i=1}^{n}\left|a_{i}-b_{i}\right|
$$

where $a$ is the calculated and $b$ is observed values of the infiltration rate and $N$ is the number of observations.

\subsubsection{One-Way Analysis of Variance}

Kostiakov's, Philip's, Horton's and Green Ampt's infiltration models were used to predict soil infiltration rate using the 55 (replicates) observed field infiltration rate. The replicates were used to compute means and standard deviation for each model and the observed in IBM SPSS version 23. One-way analysis of variance (ANOVA) was used to determine whether there are any statistically significant differences in the infiltration rates among the four different infiltration rate models and the observed at $\alpha=5 \%$ significance level. Fisher Multiple compari- 
son post hoc test was used to separate the means.

\section{Results and Discussion}

Results from Table 1 shows that the final infiltration rate for the studied site ranged from 1.2 to $42 \mathrm{~cm} / \mathrm{h}$. The final infiltration rate was higher in silt loam soil with least value of $2.8 \mathrm{~cm} / \mathrm{h}$ at site P6 - P9 and the highest value of $42 \mathrm{~cm} / \mathrm{h}$ at site P10 - P1 compared to sandy loam soil which has least value of $1.2 \mathrm{~cm} / \mathrm{h}$ and the highest value of $9 \mathrm{~cm} / \mathrm{h}$. Variations in infiltration rates are facilitated by extensive root system and animals burrowing in the soil, inadequate prewetting, and soil disturbance by the infiltration ring. The parameters of the four equations estimated using the line of best fit from the regression analysis are summarized in Table 2. The values of Kostiakov's parameter b estimated ranged between 0.55 and 0.92 (Table 2), which is in accordance with the theory of infiltration that puts the value to be positive and always less than one (Ogbe et al., 2011). The best fit model was selected on the basis of Maximum of coefficient of correlation (C.C.), minimum of Root Mean Square Error (RMSE), minimum of Maximum Absolute error (MAE) and Minimum of Mean Bias error criteria. Comparing the predicted and measured infiltration rate, the average values of C.C shown in Table 3 were computed for the four different models. The higher average values of the C.C (0.9294 - 0.9852) implies that the model accounted for almost all of the variability in the data and indicating that Philip's Green Ampt's, Kostiakov's and Horton's model provided a very good fit to the data in that order respectively.

A comparison between the measured and estimated infiltration rates as calculated from the four models is shown in Figure 2. The Kostiakov's model had the highest deviations as it overestimated the measured data in all the sampling points. The Horton's model was the next to Kostiakov model in terms of poor performance. This may be due to the fact that their parameters lack a consistent physical interpretation and also the process involved in the evaluation of the parameters might be very sensitive to approximation errors and errors due to parallax while determining the initial and steady state infiltration rates from the graph as inputs for the prediction of cumulative infiltration [17]. However, the

Table 1. Initial final and moisture contents of the study area.

\begin{tabular}{ccccc}
\hline Site & Soil type & $\begin{array}{c}\text { Initial infil. rate } \\
(\mathrm{cm} / \mathrm{h})\end{array}$ & $\begin{array}{c}\text { Final infil. rate } \\
(\mathrm{cm} / \mathrm{h})\end{array}$ & Moisture Cont. (\%) \\
\hline P7 - P8 & silt loam & 270 & 37.5 & 18.3 \\
P6 - P9 & silt loam & 36 & 2.8 & 17.5 \\
P1 - P9 & sandy loam & 24 & 3.3 & 16 \\
P13 - P14 & sandy loam & 45 & 9 & 11.5 \\
P1 - P2 & sandy loam & 24 & 1.2 & 11.8 \\
P10 - P1 & silt loam & 270 & 42 & 20 \\
\hline
\end{tabular}


Table 2. Estimated infiltration model parameters.

\begin{tabular}{ccccccccccc}
\hline \multirow{2}{*}{ Test Site } & \multicolumn{2}{c}{ Philip's model } & \multicolumn{2}{c}{ Green } & Ampt's model & \multicolumn{2}{c}{ Kostiakov's model } & \multicolumn{3}{c}{ Horton's model } \\
\cline { 2 - 10 } & $\boldsymbol{s}$ & $\boldsymbol{k}$ & $\boldsymbol{m}$ & $\boldsymbol{n}$ & $\boldsymbol{b}$ & $\boldsymbol{a}$ & $\boldsymbol{k}$ & $\boldsymbol{f}_{\boldsymbol{o}}$ & $\boldsymbol{f}_{\boldsymbol{c}}$ \\
\hline Site: P7 - P8 & 103.92 & -23.68 & 40.76 & 305.1 & 0.84 & 205.02 & 2.42 & 231.68 & 37.5 \\
Site: P6 - P9 & 14.97 & -9.26 & -2.43 & 47.68 & 0.67 & 15.08 & 5.65 & 37.67 & 2.4 \\
Site: P1 - P9 & 10.94 & -5.7 & 1.97 & 20.02 & 0.8 & 16.35 & 3.28 & 21.57 & 2.2 \\
Site: P13 - P4 & 15.16 & -0.27 & 8.88 & 57.43 & 0.92 & 40.84 & 2.03 & 33.15 & 9 \\
Site: P1 - P2 & 10.03 & -6.9 & -4.21 & 23.17 & 0.55 & 6.68 & 6.68 & 23.06 & 1.2 \\
Site: P10 - P11 & 104.78 & -10.63 & 59.43 & 2217.8 & 0.85 & 224.17 & 2.16 & 212.85 & 46.8 \\
\hline
\end{tabular}

Table 3. Performance evaluation parameters of the various infiltration models.

\begin{tabular}{|c|c|c|c|c|}
\hline Test Site & Philip's model & Horton's model & Green-Ampt's model & Kostiakov's model \\
\hline \multicolumn{5}{|c|}{ coefficient of correlation (C.C) } \\
\hline $\mathrm{P} 10$ - P11 & 0.993 & 0.9477 & 0.8986 & 0.9838 \\
\hline $\mathrm{P} 1$ - P2 & 0.9663 & 0.9079 & 0.9833 & 0.9255 \\
\hline $\mathrm{P} 13-\mathrm{P} 4$ & 0.9863 & 0.8941 & 0.985 & 0.9242 \\
\hline P1 - P9 & 0.9921 & 0.9597 & 0.9139 & SS0.9789 \\
\hline P6 - P9 & 0.9783 & 0.9289 & 0.9833 & 0.9789 \\
\hline P7 - P8 & 0.9955 & 0.9378 & 0.9536 & 0.9746 \\
\hline Average & 0.9852 & 0.9294 & 0.9529 & 0.9522 \\
\hline \multicolumn{5}{|c|}{ Root means square error (RMSE) } \\
\hline $\mathrm{P} 10-\mathrm{P} 11$ & 9.5465 & 39.8549 & 35.3858 & 127.1988 \\
\hline $\mathrm{P} 1$ - P2 & 1.9409 & 3.5617 & 1.3734 & 4.3387 \\
\hline $\mathrm{P} 13-\mathrm{P} 4$ & 1.91 & 7.3604 & 1.9929 & 25.0485 \\
\hline P1 - P9 & 0.967 & 4.354 & 3.1239 & 10.687 \\
\hline P6 - P9 & 2.215 & 5.7666 & 1.942 & 9.6733 \\
\hline P7 - P8 & 7.4405 & 44.0367 & 23.6221 & 122.1226 \\
\hline Average & 4.0033 & 1.7489 & 11.24 & 49.8448 \\
\hline \multicolumn{5}{|c|}{ Mean absolute error (MAE) } \\
\hline P10 - P11 & 7.1456 & 35.2567 & 32.7114 & 121.52 \\
\hline P1 - P2 & 1.6478 & 2.7967 & 1.1234 & 3.9711 \\
\hline $\mathrm{P} 13-\mathrm{P} 4$ & 1.3022 & 6.6778 & 3.9716 & 23.7778 \\
\hline P1 - P9 & 0.7733 & 4.0167 & 2.8773 & 9.9289 \\
\hline P6 - P9 & 1.746 & 5.041 & 1.5755 & 93.573 \\
\hline P7 - P8 & 6.19 & 42.0922 & 21.6556 & 116.0711 \\
\hline Average & 3.1341 & 15.9802 & 10.6525 & 61.4736 \\
\hline \multicolumn{5}{|c|}{ Mean bias error (MBE) } \\
\hline $\mathrm{P} 10$ - P11 & 0.1944 & 14.6522 & -0.0034 & 121.52 \\
\hline P1 - P2 & 0.0189 & 1.6278 & 0.0033 & 2.3867 \\
\hline $\mathrm{P} 13-\mathrm{P} 4$ & 0.0267 & 3.6978 & 0.0015 & 23.7778 \\
\hline P1 - P9 & 0.02 & 3.0344 & -0.003 & 9.9289 \\
\hline P6 - P9 & 0.026 & 4.175 & -0.003 & 8.438 \\
\hline P7 - P8 & 0.1856 & 30.2656 & 0 & 116.0711 \\
\hline Average & 0.0786 & 9.5755 & -0.0007 & 47.0204 \\
\hline
\end{tabular}



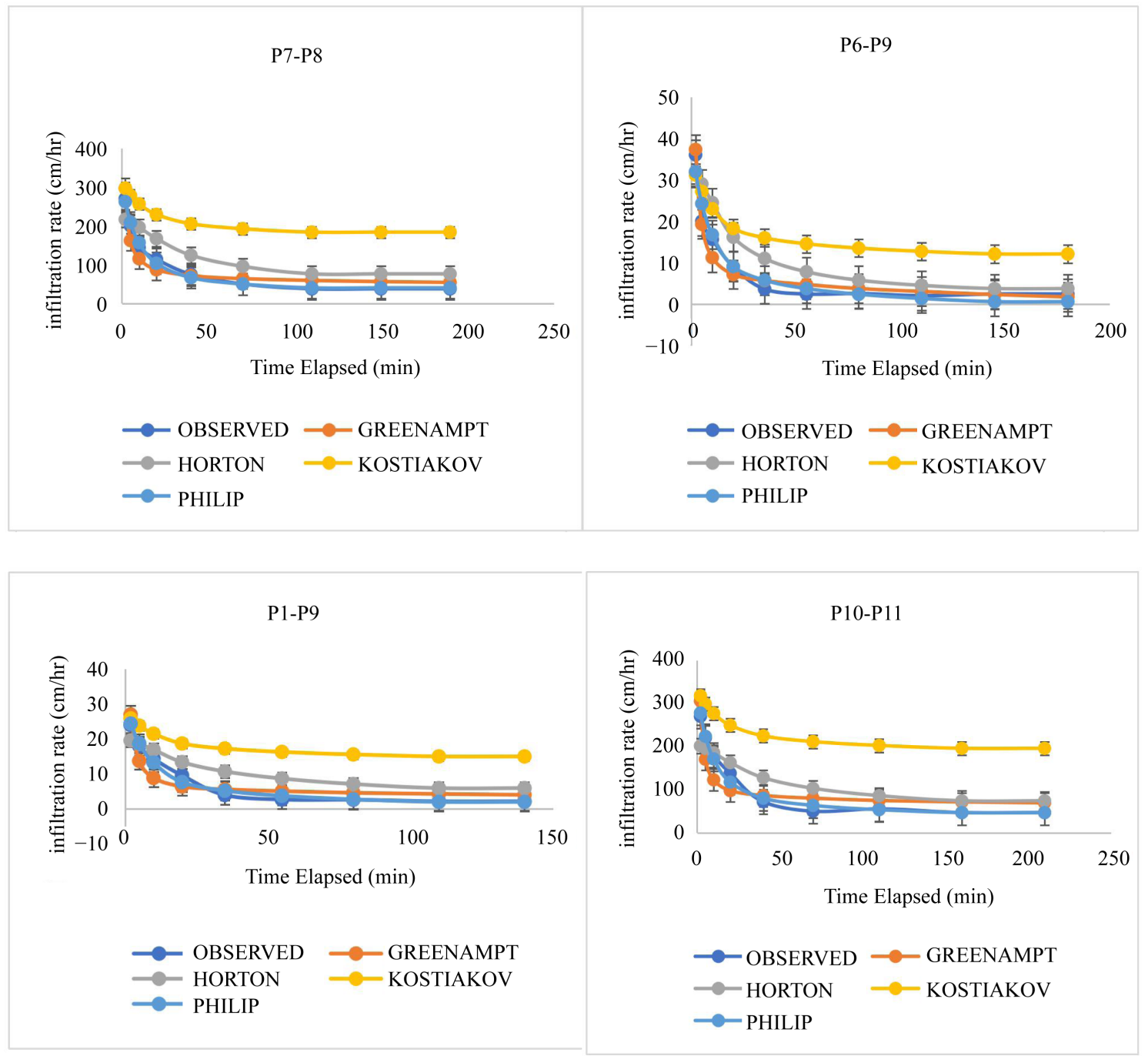

Figure 2. Comparison of measured infiltration rate with various models estimated infiltration rate for the study area.

infiltration rate estimated by the Philip's model was the most successful in predicting fitting measured experimental data.

Statistical results from Table 4 indicates that the infiltration rate differed significantly $(F(4)=3.89, \mathrm{p}<0.01)$ across the different models. The Fisher's multiple comparison test revealed that the mean infiltration rate estimated from the Green Ampt's (44.44 \pm 8.81), Horton's (53.92 \pm 8.9), and Philip's (44.52 \pm 9.11$)$ model were not significantly different $(p>0.05)$ from the observed $(44.44 \pm$ 9.12). However, the mean infiltration rate predicted by the Kostiakov's (90.76 \pm 13.95) model was significantly higher than the other models (Table 4).

The average values of the RMSE were 4.0033, 17.489, 11.2400 and 49.8448, MAE were 3.1341, 15.9802, 10.6525, and 61.4736, and MBE were 0.0786, 9.5755, -0.0007 and 47.0204 for Philip, Horton, Green Ampt and Kostiakov respectively for the entire study area (Table 4). Comparison of the statistical parameters RMSE, MBE, and MAE indicates that the Philip's model agreed well with the 
Table 4. Mean and standard error of observed and predicted infiltration rate.

\begin{tabular}{ccc}
\hline Methods & Mean Infiltration rate $(\mathrm{cm} / \mathrm{h})$ & Std. Error of Mean $(\mathrm{cm} / \mathrm{h})$ \\
\hline Observed & $44.44 \mathrm{~b}$ & 9.12 \\
Green Ampt & $44.44 \mathrm{~b}$ & 8.81 \\
Horton & $53.92 \mathrm{~b}$ & 8.90 \\
Kostiakov & $90.76 \mathrm{a}$ & 13.95 \\
Philip & $44.52 \mathrm{~b}$ & 9.11 \\
F-ratio & 3.89 & \\
df & 4 & \\
$P$-value & 0.004 & \\
\hline
\end{tabular}

Means that do not share a letter are significantly different by Fisher's multiple comparison test.

measured data and therefore, performed better than the Green Ampt's, Horton's and Kostiakov's models respectively in that order for Besease wetland soils. This result corroborates with the findings of [18], who assessed six infiltration equations on a homogeneous coarse textured soils and found out that the Philip's model gave a very good representation of the infiltration while Kostiakov, modified Kostiakov, Green Apmt and Holtan Overton performed in that order respectively as adduced by [17]. [1] also predicted cumulative infiltration under the Inceptisols in the humid forest zones. The result showed that Philip's model was more suitable than the Kostiakov model. However, the results of this study is in contrast to the research conducted by [19] who reported that Kostiakov model related closely to the measured data than Philip's model for a hydromorphic soil at Samura, Nigeria. Thus, infiltration models should be tested for their ability to estimate the final infiltration rate for each location and should be documented at each site [20]. One or few of the infiltration models are better and for a specific site condition [21], [1] which presupposes that not all models are applicable in all soils. Consequently, the application of these models under verified field conditions leads to the determination of the appropriate infiltration characteristics for the equations that would optimize infiltration simulation, irrigation performance and minimize water wastage [12].

\section{Conclusions}

The prediction accuracy of four infiltration models was validated with measured values using the double ring infiltrometer. Comparison of the field and predicted infiltration rate indicated that the infiltration rate predicted by the Philip's model was much closer to the observed data. The statistical results of C.C show that infiltration rate can be predicted by the Philip, Green Ampt, Horton and Kostiakov models, respectively.

Statistical results also from the Fisher's multiple comparison test show that the mean infiltration rate estimated from the Green Ampt's, Philip's and Horton's model was not significantly different $(p>0.05)$ from the observed. 
Based on the mean values of RMSE, MAE and MBE values, the Philip's model provided the lowest values and could be deduced that infiltration rate was well described by this model. Quantification of infiltration rate by this model will be of importance in the design of irrigation schemes and scheduling of irrigation. Therefore, in the absence of measured infiltration data, the Philip's model could be employed to generate infiltration information for inland valley bottom soils that exhibit similar characteristics of Besease wetland soils.

\section{Acknowledgements}

The authors acknowledged the Ministry of Food and Agriculture (MoFA) for providing monetary support to this research work and Mr. Frank Boakye of Grains Development Board, a subsidiary of MoFA for assisting in conducting field work.

\section{Conflicts of Interest}

The studies reported in this publication, were supported by a grant from the Ministry of Food and Agriculture (MoFA), Ghana. The author is a lecturer at the University of Energy and natural Resources, Ghana. The terms of this arrangement have been reviewed and approved by the University of Energy and natural Resources at Sunyani in accordance with its policy on objectivity in research.

\section{References}

[1] Oku, E. and Aiyelari, A. (2011) Predictability of Philip and Kostiakov Infiltration Model under Inceptisols in the Humid Forest Zone, Nigeria. Kasetsart Journal (Natural Science), 45, 594-602.

[2] Angelaki, A., Sakellariou-Makrantonaki, M. and Tzimopoulos, C. (2013) Theoretical and Experimental Research of Cumulative Infiltration. Transport in Porous Media, 100, 247-257. https://doi.org/10.1007/s11242-013-0214-2

[3] Mudiare, O.J. and Adewunmi, J.K. (2000) Estimation of Infiltration from Field-Measured Sorptivity Values. Nigerian Journal of Soil Science Research, 1, 1-3.

[4] Ogban, P.L., Madeakor, O. and Akwe, I.P. (2000) Infiltration Characteristics and Erosion Potentials of Catenary Soils in Southeastern, Nigeria. In: Babalola, O., Ed., Proceedings of the 26th Annual Conference of the Soil Science Society of Nigeria, Ibadan, Nigeria, 90-93.

[5] Adeniji, F.A., Umara, B.G., Dibal, J.M. and Amali, A.A. (2013) Variation of Infiltration Rates with Soil Texture. A Laboratory Study. International Journal of Engineering and Innovative Technology, 3, 454-459.

[6] Turner, E.R. (2006) Comparison of Infiltration Equations and Their Field Validation with Rainfall Simulation. PhD Thesis, University of Maryland, Baltimore, MD.

[7] Sihag, P., Tiwari, N.K. and Ranjan, S. (2017) Estimation and Inter-Comparison of Infiltration Models. Water Science, 31, 34-43. https://doi.org/10.1016/j.wsj.2017.03.001

[8] Vand, S.A., Sihag, P., Singh, B. and Zand, M. (2018) Comparative Evaluation of Infiltration Models. KSCE Journal of Civil Engineering, 22, 4173.

https://doi.org/10.1007/s12205-018-1347-1 
[9] Singh, B., Sihag, P. and Singh, K. (2018) Comparison of Infiltration Models in NIT Kurukshetra Campus. Applied Water Science, 8, 63. https://doi.org/10.1007/s13201-018-0708-8

[10] Dagadu, J.S. and Nimbalkar, P.T. (2012) Infiltration Studies of Different Soils under Different Soil Conditions and Comparison of Infiltration Models with Field Data. International Journal of Advance Engineering Technology, 3, 154-157.

[11] Ogbe, V.B., Jayeoba, O.J. and Ode, S.O. (2011) Comparison of Four Soil Infiltration Models on A Sandy Soil in Lafia, Southern Guinea Savanna Zone of Nigeria. Production Agriculture and Technology, Nasarawa State University Journal, 7, 116-126.

[12] KankamYeboah, K., Duah, A. A., and Mensah, F.K. (1997) Design and Construction of Hund Dug Wells at Besease Technical Report. Water Research Institute (CSIR), Accra, Ghana, 16.

[13] Kostiakov, A.N. (1932) On the Dynamics of the Coefficient of Water Percolation in Soils and the Necessity for Studying It from a Dynamic Point of View for Purposes of Amelioration. In: Transactions of the Sixth Commission of the International Society of Soil Science, Part A, Russia, 17-21.

[14] Philip, J.R. (1957) The Theory of Infiltration: 2. The Profile at Infinity. Soil Science, 83, 435-448. https://doi.org/10.1097/00010694-195706000-00003

[15] Horton, R. E. (1940) Approach toward a Physical Interpretation of Infiltration Capacity. Soil Science Society of America Journal, 5, 339-417. https://doi.org/10.2136/sssaj1941.036159950005000C0075x

[16] Green, W.H. and Ampt, G.A. (1911) Studies on Soil Physics, 1: The Flow of Air and Water through Soils. The Journal of Agricultural Science, 4, 1-24. https://doi.org/10.1017/S0021859600001441

[17] Igbadun, H., Othman, M. and Ajayi, A. (2016) Performance of Selected Water Infiltration Models in Sandy Clay Loam Soil in Samaru Zaria. Global Journal of Researches in Engineering. Journal of General Engineering, 16, 8-14.

[18] Saadi, A. and Al-Azawi, S.A. (1985) Experimental Evaluation of Infiltration Models. Journal of Hydrology, 24, 77-88.

[19] Igbadun, H.E. and Idris, U.D. (2007) Performance Evaluation of Infiltration Models in a Hydromorphic Soil. Nigerian Journal of Soil and Environmental Research, 7, 53-59. https://doi.org/10.4314/njser.v7i1.28418

[20] Haghighi, F., Gorji, M., Shorafa, M. and Sarmadian, F. (2010) Evaluation of Some Infiltration Models and Hydraulic Parameters. Spanish Journal of Agricultural Research, 8, 210-216. https://doi.org/10.5424/sjar/2010081-1160

[21] Machiwal, D., Jha, M.K. and Mal, B.C. (2006) Modelling Infiltration and Quantifying Spatial Soil Variability in a Watershed of Kharagpur, India. Biosystems Engineering, 95, 569-582. https://doi.org/10.1016/j.biosystemseng.2006.08.007 